\title{
Good continuation affects discrimination of visual pattern information in young infants
}

\author{
PAUL C. QUINN \\ University of Delaware, Newark, Delaware \\ and \\ RAMESH S. BHATT \\ University of Kentucky, Lexington, Kentucky
}

\begin{abstract}
A familiarization-novelty preference procedure was used to determine whether 3- to 4-month-old and 6- to 7-month-old infants utilize the Gestalt principle of good continuation to organize visual patterns. The study involved presentation of a target item (i.e., a square or diamond) either in-line or off-line with a set of distractor items (i.e., circles). Infants in both age groups responded to a change in the target element in the off-line, but not in the in-line, condition. The results suggest that infants organize visual pattern information in accord with the principle of good continuation. Implications of this finding for models of the ontogenesis and microgenesis of object perception in infants and adults are discussed.
\end{abstract}

Processes of perceptual organization are believed to provide representations that form coherent units in the visual cognition system of adults (Palmer, 1999). Recent investigations of perceptual grouping by adults have been informative in (1) introducing new organizational principles (Palmer, 1992; Palmer \& Rock, 1994), (2) providing evidence that grouping can occur at early or late stages of visual processing (Palmer, Brooks, \& Nelson, 2003; Peterson \& Gibson, 1994), and (3) suggesting that various Gestalt principles are differentially powerful or operational at different times in the overall course of processing (Ben-Av \& Sagi, 1995; Han, Humphreys, \& Chen, 1999; Kurylo, 1997). This work has led to a newly emerging view that perceptual organization is not a monolithic phenomenon, but, rather, represents a confluence of multiple processes (Behrmann \& Kimchi, 2003).

Given Gestalt claims that perceptual grouping reflects the activity of a nervous system that comes preconstructed to impose organization upon first presentation of a visual pattern (Köhler, 1929), developmental research conducted over the last decade has begun to investigate the origins and development of perceptual unit formation during infancy. Investigations have focused on (1) identifying the grouping principles that lead to organized representations of visual pattern information (Quinn, Brown, \& Streppa,

This research was supported by NIH Grants HD-42451 and HD46526. The authors thank Laurie Yarzab for assistance in testing participants and Jason Reiss for help in creating Figure 1. The authors also thank W. Todd Maddox, Alan Slater, and two anonymous reviewers for comments on the initial submission. Address correspondence to P. C. Quinn, Department of Psychology, University of Delaware, Newark, DE 19716 (e-mail: pquinn@udel.edu).
1997; Quinn, Burke, \& Rush, 1993), (2) determining the time course of development of the principles (Farroni, Valenza, Simion, \& Umiltà, 2000; Johnson \& Aslin, 1995), and (3) understanding the developmental factors (i.e., maturation and experience) that affect the emergence of the different principles (Johnson \& Aslin, 1996; Kellman, 1996; Needham \& Kaufman, 1997; Quinn \& Bhatt, 2005; Spelke, 1982). In accord with the theoretical trend in the adult literature, the data suggest that different organizational principles may become functional over different time courses of development and that not all principles are automatically deployed in the manner originally proposed by Gestalt theorists (Quinn, Bhatt, Brush, Grimes, \& Sharpnack, 2002). As a consequence, current work is examining the functionality of a range of organizational principles with a variety of stimuli (Johnson, 1998; Needham \& Ormsbee, 2003; Quinn, 2006).

The focus of the present study is to investigate whether infants organize visual pattern information in accord with the principle of good continuation or continuity (Wertheimer, 1923/1958). In studies conducted with adults, there have been conflicting reports about the strength and timing of good continuation as a grouping principle. For example, Kurylo (1997) reported that grouping by good continuation required more processing time than did grouping by proximity, thereby suggesting a late deployment for good continuation in the sequence of visual processing operations. However, Behrmann and Kimchi (2003) have argued that good continuation is easily adhered to as a grouping principle, even by patients with visual agnosia, and is likely to be accomplished by early visual processes (see also Pomerantz, 1981, 1983). This idea has received additional support from neuroimaging and electrophysiological studies suggesting that good continuation grouping is based on 
the neural transactions occurring in V1 and V2 of the visual cortex (Lamme \& Roelfsema, 2000; Lee, 2003; Sugita, 1999; Westheimer, 1999).

The developmental literature has also been conflicted as to the power, age of onset, and determinants of good continuation grouping in children and infants. Historically older work conducted with children indicated that good continuation was operational throughout the schoolage years and even dominated other principles, including proximity and shape similarity, in cue competition tasks (Rush, 1937). However, subsequent investigations conducted with infants have demonstrated that 4-montholds presented with the top and bottom pieces of a centeroccluded object (1) did not perceive the continuity of the object even when the pieces were aligned and similar and (2) did perceive the continuity of the object (i.e., represented the pieces as one connected unit) as long as the two pieces moved together and even when the pieces could not be grouped in accord with organizational principles such as good continuation and similarity (Kellman \& Spelke, 1983). A theoretical account of the development of unit formation that has emerged from the findings on the representation of partly occluded objects by infants includes two processes (Kellman, 1996), one of which is a "primitive" edge-insensitive (EI) process that is available at birth and responds to common movement information (but see Slater et al., 1990), whereas the other is a "rich" edge-sensitive (ES) process that becomes available at around 6-7 months of age and responds to good continuation information. These processes are hypothesized to reflect the operation of modular input systems (Fodor, 1983) that differ in their maturationally based time courses of deployment.

Additional evidence relevant to the issue of whether infants adhere to good continuation in the perception of visual pattern information includes the results of developmental studies of the perception of subjective contours. Some investigations have reported that infants perceive subjective contours in the age range between 7 and 8 months, but not between 4 and 6 months (Bertenthal, Campos, \& Haith, 1980; Csibra, Davis, Spratling, \& Johnson, 2000). However, Ghim (1990) has reported perception of subjective contours in infants as young as 3-4 months. Although Ghim's experimental design has been criticized because of the possibility that infants could have relied on local cues to perform at above-chance levels (Csibra et al., 2000; Kellman \& Arterberry, 1998), Kavsek (2002) has produced evidence that infants as young as 4 months can perceive subjective contours, as long as the infants are tested with a paired comparison procedure and the distance between the inducing elements is kept small. Moreover, Johnson and Mason (2002) have suggested that even 2-month-olds can perceive subjective contours with the addition of motion to the perceptual displays.

Another bit of data bearing on the issue of whether infants perceive visual patterns in a manner predicted by the good continuation principle comes from a study in which 3-and 4-month-old infants were presented with contours that adults organize into overlapping square and circle shapes, rather than equally familiar pacman-type shapes (Quinn et al., 1997; see also Quinn \& Schyns, 2003). Specifically, the infants were familiarized with an overlapping square-circle configuration and then preference tested with the circle versus one pacman shape and the square versus another pacman shape. Despite the fact that all of the test shapes were equally familiar, the infants were found to prefer the pacman shapes over both the circle and the square shapes, and the preferences were found not to be attributable to a priori preferences. These findings suggest that infants were successful at organizing the contours of the pattern into the circle and square shapes in adherence with the Gestalt principle of good continuation.

A summary view of the evidence suggests that infants younger than 6-7 months of age do not group visual pattern information in accord with good continuation when the elements to be connected are partially occluded or physically unconnected and distant from one another (Bertenthal et al., 1980; Csibra et al., 2000; Kellman \& Spelke, 1983). However, young infants appear to be able to utilize good continuation as a grouping principle when the elements to be grouped are completely visible and are already physically connected or are disconnected but in close physical proximity (Kavsek, 2002; Quinn et al., 1997; Quinn \& Schyns, 2003). The review of the findings thus suggests that young infants' use of good continuation as an organizational principle is context dependent, an account that also characterizes infant performance in other developmental domains, such as physical reasoning and memory (Baillargeon, 2002; Rovee-Collier, 1997), but that stands in contradistinction with a strict maturationally based explanation of the data (Kellman, 1996).

Because of the mixed results on infants' use of good continuation, we undertook an investigation to determine whether discrimination of visual patterns in infants is affected by good continuation, using a task that has been shown to affect detection of visual pattern information in adults (Prinzmetal \& Banks, 1977). Given the debate over whether good continuation is available in infants younger than 6-7 months of age, two age groups of infants, 3- to 4-month-olds and 6- to 7-month-olds, were tested. The task originated in a line of adult research in which participants were asked to detect targets under conditions in which the targets did or did not group with background stimuli (Banks \& Prinzmetal, 1976; see also Pani, Mervis, \& Robinson, 1999). Prinzmetal and Banks (1977) reported that a target item (i.e., a T or an F) was detected more slowly when it was presented in line with noise elements (i.e., $\mathrm{T}-\mathrm{F}$ hybrids) than when it appeared off line from noise elements. This result was interpreted as evidence for the use of good continuation. In the in-line condition, adults grouped the elements in the line into a single, larger unit of processing, with the consequence that the component elements lost their status as individuated smaller units of processing and could be identified only upon subsequent analysis. In contrast, in the off-line condition, the target element was not perceived as part of the group, thereby becoming an independent processing unit, receiving full analysis. 
In the present study, we adapted the Prinzmetal and Banks (1977) methodology to determine whether 3- to 4-month-olds and 6- to 7-month-olds perceive visual patterns in accord with the principle of good continuation, using squares and diamonds (instead of Ts and Fs) as targets and circles (instead of hybrid T-Fs) as distractors. The stimuli and experimental design are depicted in Figure 1. As is shown in panels A and B, the infants were familiarized with a stimulus in which the target element (either a square or a diamond) appeared either in line or off line with the noise elements (circles). Both groups were then tested for their preference between the familiar pattern and a pattern containing a novel target element. If the good continuation principle is in operation, infants should display a more reliable preference for the stimulus with the novel target element in the off-line condition, as compared with the in-line condition.

\section{METHOD}

\section{Participants}

The participants were 64 infants, thirty-two 3- to 4-month-olds (13 females) with a mean age of 101.03 days $(S D=14.30$ days) and thirty-two 6- to 7-month-olds (16 females) with a mean age of 200.16 days $(S D=11.20$ days). Five additional 3- to 4-month-olds were tested, but 3 failed to complete the procedure, due to fussiness, and 2 were excluded from the data analysis because of a position preference that entailed looking to one side of the display $95 \%$ or more of the total looking time $(n=1)$ or failure to compare the test stimuli $(n=1)$. Two additional 6- to 7-month-olds were tested but did not complete the procedure, due to fussiness.

\section{Stimuli}

Each stimulus consisted of six black elements positioned on a $17.7 \times 17.7 \mathrm{~cm}$ white card (see Figure 1). The elements included five circles (diameter $=0.24 \mathrm{~cm}$ ) and either a square or a diamond $(0.24 \mathrm{~cm}$ per side) and were spaced $1 \mathrm{~cm}$ apart. The in-line elements formed a line oriented $45^{\circ}$ clockwise from horizontal; the off-line element was positioned next to the middle element of the line so that the middle element and off-line element were oriented along a diagonal that was $45^{\circ}$ counterclockwise from horizontal.

\section{Apparatus}

All the infants were tested in a visual preference apparatus, modeled after the one described by Fagan (1970). The apparatus was a large, three-sided gray viewing chamber that was on wheels. It had a hinged, gray display panel, onto which were attached two compartments to hold the posterboard stimuli. The stimuli were illuminated by a fluorescent lamp that was shielded from the infant's view. The center-to-center distance between compartments was $30.5 \mathrm{~cm}$, and on all trials, the display panel was situated approximately $30.5 \mathrm{~cm}$ in front of the infant. There was a $0.62-\mathrm{cm}$ peephole located midway between the two display compartments that permitted an observer to record the infant's visual fixations. A second peephole, $0.90 \mathrm{~cm}$ in diameter, was located directly below the first peephole and permitted a Pro Video CVC-120PH pinhole camera and a JVC video recorder to record the infants' gaze duration.

\section{Procedure}

All the infants underwent the following general procedure. They were brought to the laboratory by a parent and were seated in a reclining position on the parent's lap. There were two experimenters, both of whom were naive to the hypotheses under investigation. The first experimenter positioned the apparatus so that the midline of the infant's head was aligned with the midline of the display panel. When the display panel was open, the infant could see the experimenter from the midsection up, in addition to a portion of the room that was a light background color. The experimenter selected the appropriate stimuli and loaded them into the compartments of the display panel from a nearby table. The experimenter then elicited the infant's attention and closed the panel, thereby exposing the stimuli to the infant. The parent was unable to see the stimuli.

During each trial, the first experimenter observed the infant through the small peephole and recorded visual fixations to the left and right stimuli by means of two $605 \mathrm{XE}$ Accusplit electronic stop watches, one of which was held in each hand. Interobserver agreement, as determined by comparing the looking times measured by the experimenter using the center peephole, and by an additional naive observer measuring looking times off line from videotape records,

\section{Familiar Stimulus}

(A)
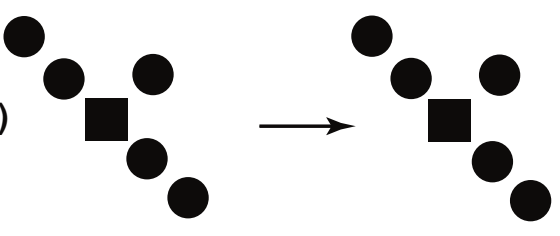

Test Stimuli

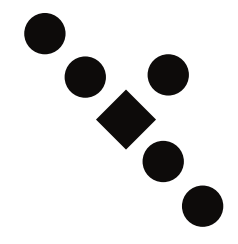

(B)
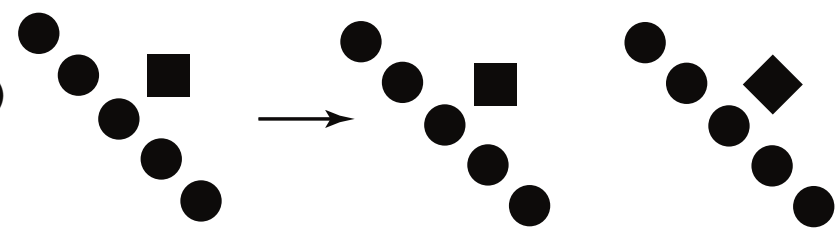

Figure 1. Examples of the familiarization and test stimuli. The in-line condition is depicted in panel $A$; the off-line condition is shown in panel B. Experimental design was fully counterbalanced so that for half of the infants in each condition, the target element in the familiar stimulus was a square; for the other half, it was a diamond. 
was calculated for 16 infants and averaged $93 \%$. Between trials, the experimenter opened the panel, recorded infant looking times, reobtained the infant's attention, recentered his or her gaze, and closed the panel. The first and second experimenters changed places for the test trials. The experimenter who presented stimuli and measured infant fixations during familiarization now measured trial duration and signaled the end of each test trial, whereas the second experimenter presented the test stimuli and measured infant fixations. The second experimenter was always naive with respect to the familiar stimulus. The two experimenters changed roles across infants.

Sixteen infants in each age group were randomly assigned to each of two experimental groups. Infants in the off-line group were familiarized with the target item appearing outside of the diagonal line of circle elements. Infants in the in-line group were familiarized with the target item appearing in line with the diagonal of circle elements. For half of the infants in each group, the target element was a square; for the other half, it was a diamond. For both groups, there were four 15 -sec familiarization trials. On each trial, two identical copies of the familiar stimulus were presented. Both groups were then administered a preference test in which the familiar stimulus was paired with a stimulus displaying a novel target element. There were two 10 -sec preference test trials. The left-right positioning of the novel and familiar stimuli was counterbalanced across infants on the first test trial and was reversed on the second test trial.

\section{RESULTS}

\section{Familiarization Trials}

Individual looking times were summed over the left and right copies of the stimulus on each trial and then averaged across the first two trials and the last two trials. The mean fixation times, along with their standard deviations, are shown in Table 1. An ANOVA with trial block (1-2 vs. $3-4)$, age (3-4 months vs. 6-7 months), and experimental condition (in line vs. off line) as factors, performed on the individual looking-time scores, revealed main effects of trial block $[F(1,60)=13.10, p<$ $.001]$ and age $[F(1,60)=6.76, p=.011]$. These effects indicate that (1) both age groups habituated to the stimuli presented during familiarization (Cohen \& Gelber, 1975) and (2) the younger infants looked more to these stimuli than did the older infants, a finding that is typical of prior reports of looking-time performance for infants in this age range (e.g., Quinn et al., 2002). No other effects were significant.

\section{Preference Test Trials}

For each infant, a novelty preference score was calculated by dividing the looking time to the novel stimulus by the looking time to both stimuli during the preference test. Mean novelty preference scores are presented in Table 1. An ANOVA performed on the individual preference scores, with factors of experimental condition and age, yielded only a main effect of condition $[F(1,60)=6.23, p=.014]$, indicating that novelty preference scores were higher in the off-line than in the in-line condition. Comparisons of the mean preference scores to the chance value of $50 \%$ revealed that both age groups looked reliably longer to the novel stimulus in the off-line, but not in the in-line, condition. The findings suggest that the discrimination performance of both age groups was affected by the good continuation of the visual pattern information.

\section{DISCUSSION}

Both 3- to 4-month-olds and 6- to 7-month-olds discriminated a change in an element if it was isolated from a continuous pattern, but not if it was part of a continuous pattern. These results indicate that the performance of both younger and older infants was affected by continuity. In this respect, infants' performance was similar to that of adults in the Prinzmetal and Banks (1977) study.

The finding that 3- to 4-month-olds are sensitive to continuity as a perceptual organizing principle is inconsistent with developmental accounts of unit formation that maintain that ES processing is not available until 6-7 months of age (Kellman, 1996). ${ }^{1}$ The present data are more consistent with other reports that suggest the emergence of ES processes earlier in life (e.g., Bhatt \& Bertin, 2001; Ghim, 1990; Johnson \& Aslin, 1996; Kavsek, 2002; Quinn et al., 1997; Quinn \& Schyns, 2003). It is worth noting that the continuity that affected the infants' performance in the present study was not based on an uninterrupted contour, as was the case in Quinn et al. (1997) and Quinn and Schyns (2003), or on similar inducing elements, as was true in the studies of subjective contour perception (Ghim, 1990; Kavsek, 2002). Rather, the continuity was derived from the relatability of disparate pattern elements. The present results thus suggest that the ability to bridge gaps between individual and contrasting elements to infer continuity is present as early as $3-4$ months of age.

The present data and other reports of infants' sensitivity to perceptual organization suggest that Gestalt principles are operational near the beginning of development. This does not imply, however, that perceptual organization does not undergo any developmental change and that all Gestalt principles are equally available from birth. Prior research has established that young infants are sometimes unable to utilize organizational cues under conditions in which older infants and adults are able to utilize the same cues (e.g., Bertenthal et al., 1980; Csibra et al., 2000; Kellman \& Spelke, 1983; Quinn et al., 2002). This implies that, although even young infants may be sensitive to perceptual organizational principles such as continuity,

Table 1

Mean Fixation Times (in Seconds) During the Familiarization Trials and Mean Novelty Preference Scores (as Percentages) During the Test Trials

\begin{tabular}{|c|c|c|c|c|c|c|c|}
\hline \multirow{3}{*}{$\begin{array}{c}\text { Target } \\
\text { Element }\end{array}$} & \multicolumn{4}{|c|}{ Fixation Time } & & & \\
\hline & \multicolumn{2}{|c|}{ Trials 1-2 } & \multicolumn{2}{|c|}{ Trials 3-4 } & \multicolumn{3}{|c|}{ Novelty Preference } \\
\hline & $M$ & $S D$ & $M$ & $S D$ & $M$ & $S D$ & $t$ \\
\hline \multicolumn{8}{|c|}{ 3- to 4-Month-Olds } \\
\hline Grouped & 8.36 & 3.46 & 6.83 & 3.28 & 50.87 & 14.09 & 0.25 \\
\hline Ungrouped & 7.78 & 2.75 & 6.36 & 3.35 & 59.09 & 16.50 & $2.20^{*}$ \\
\hline \multicolumn{8}{|c|}{ 6- to 7-Month-Olds } \\
\hline Grouped & 6.04 & 2.44 & 4.81 & 2.69 & 46.13 & 19.45 & -0.80 \\
\hline Ungrouped & 6.02 & 3.33 & 5.26 & 3.26 & 58.82 & 16.51 & $2.14^{*}$ \\
\hline
\end{tabular}

Note $-t$ tests compared mean preference scores with chance performance. ${ }^{*} p<.05$. 
as was demonstrated in the present study, the ease with which these principles are utilized may undergo developmental change. The developmental change may be characterized, in part, by observing the principles initially emerge in relatively simple perceptual contexts (e.g., 2-D displays, elements completely visible) and subsequently become applicable in more complex perceptual environments (e.g., 3-D displays, elements partially occluded). An account of this nature could help to explain the failure to observe ES processing reported in some investigations conducted with young infants (Kellman \& Arterberry, 1998), but without having to hypothesize the absence of an ES process as the underlying mechanism.

The findings of a developmentally early emergence for good continuation in young infants are consistent with the results suggesting that good continuation reflects the operation of mechanisms deployed early in the time course of visual processing in adults (Behrmann \& Kimchi, 2003). This correspondence between ontogenesis and microgenesis is supportive of an orthogenic approach to understanding perceptual organization (Burack, Enns, Iarocci, \& Randolph, 2000; Werner, 1957), one in which change at different time scales is marked by progression from an initial unanalyzed, global state to a more mature state characterized by increased differentiation. Interestingly, the match between ontogenesis and microgenesis in perceptual organization is also observed in perceptual categorization (Quinn, 2002; Quinn \& Johnson, 2000; Rogers \& McClelland, 2004), thereby supporting the usefulness of an orthogenic approach for a unified explanation of change occurring within mind-brain systems.

\section{REFERENCES}

Baillargeon, R. (2002). The acquisition of physical knowledge in infancy: A summary in eight lessons. In U. Goswami (Ed.), Blackwell handbook of childhood cognitive development (pp. 47-83). Oxford: Blackwell.

Banks, W. P., \& Prinzmetal, W. (1976). Configurational effects in visual information processing. Perception \& Psychophysics, 19, 361367.

Behrmann, M., \& Kimchi, R. (2003). What does visual agnosia tell us about perceptual organization and its relationship to object perception? Journal of Experimental Psychology: Human Perception \& Performance, 29, 19-42.

Ben-Av, M. B., \& SAgI, D. (1995). Perceptual grouping by similarity and proximity: Experimental results can be predicted by intensity autocorrelations. Vision Research, 35, 853-866.

Bertenthal, B. I., Campos, J. J., \& Haith, M. M. (1980). Development of visual organization: Perception of subjective contours. Child Development, 51, 1072-1080.

Bhatt, R. S., \& Bertin, E. (2001). Pictorial cues and three-dimensional information processing in early infancy. Journal of Experimental Child Psychology, 80, 315-332.

Burack, J. A., Enns, J. T., Iarocci, G., \& Randolph, B. (2000). Age differences in visual search for compound patterns: Long- versus short-range grouping. Developmental Psychology, 36, 731-740.

Cohen, L. B., \& Gelber, E. R. (1975). Infant visual memory. In L. B. Cohen \& P. Salapatek (Eds.), Infant perception: From sensation to cognition (Vol. 1, pp. 347-403). New York: Academic Press.

Csibra, G., Davis, G., Spratling, M. W., \& Johnson, M. H. (2000). Gamma oscillations and object processing in the infant brain. Science, 290, 1582-1585.
FAGAN, J. F. (1970). Memory in the infant. Journal of Experimental Child Psychology, 9, 217-226.

Farroni, T., Valenza, E., Simion, F., \& Umiltà, C. (2000). Configural processing at birth: Evidence for perceptual organisation. Perception, 29, 355-372.

Fodor, J. (1983). The modularity of mind. Cambridge, MA: MIT Press.

GHIM, H. R. (1990). Evidence for perceptual organization in infants: Perception of subjective contours by young infants. Infant Behavior \& Development, 13, 221-248.

Han, S., Humphreys, G. W., \& Chen, L. (1999). Uniform connectedness and classical Gestalt principles of perceptual grouping. Perception \& Psychophysics, 61, 661-674.

JoHNSON, S. P. (1998). Object perception and object knowledge in young infants: A view from studies of visual development. In A. Slater (Ed.), Perceptual development: Visual, auditory and speech perception in infancy (pp. 211-239). Hove, U.K.: Psychology Press.

Johnson, S. P., \& AsLin, R. N. (1995). Perception of object unity in 2month-old infants. Developmental Psychology, 31, 739-745.

Johnson, S. P., \& AsLin, R. N. (1996). Perception of object unity in young infants: The roles of motion, depth, and orientation. Cognitive Development, 11, 161-180.

Johnson, S. P., \& MAsON, U. (2002). Perception of kinetic illusory contours by 2-month-old infants. Child Development, 73, 22-34.

KavseK, M. J. (2002). The perception of static subjective contours in infancy. Child Development, 73, 331-344.

Kellman, P. J. (1996). The origins of object perception. In R. Gelman $\& \mathrm{~T}$. K. Au (Eds.), Perceptual and cognitive development (Handbook of perception \& cognition, 2nd ed., pp. 3-48). San Diego: Academic Press.

Kellman, P. J. (2003). Visual perception of objects and boundaries: A four-dimensional approach. In R. Kimchi, M. Behrmann, \& C. R. Olson (Eds.), Perceptual organization in vision: Behavioral and neural perspectives (pp. 155-201). Mahwah, NJ: Erlbaum.

Kellman, P. J., \& ARTERBERry, M. E. (1998). The cradle of knowledge: Development of perception in infancy. Cambridge, MA: MIT Press.

Kellman, P. J., \& SpelKe, E. S. (1983). Perception of partly occluded objects in infancy. Cognitive Psychology, 15, 483-524.

KöHLER, W. (1929). Gestalt psychology. New York: Liveright.

KuRYLO, D. D. (1997). Time course of perceptual grouping. Perception \& Psychophysics, 59, 142-147.

Lamme, V. A. F., \& Roelfsema, P. R. (2000). The distinct modes of vision offered by feedforward and recurrent processing. Trends in Neurosciences, 23, 571-579.

LEE, T. (2003). Neural basis of attentive perceptual organization. In R. Kimchi, M. Behrmann, \& C. R. Olson (Eds.), Perceptual organization in vision: Behavioral and neural perspectives (pp. 431-457). Mahwah, NJ: Erlbaum.

NeEdHam, A., \& KaUfman, J. (1997). Infants' integration of information from different sources in object segregation. Early Development \& Parenting, 6, 137-147.

Needham, A., \& Ormsbee, S. M. (2003). The development of object segregation during the first year of life. In R. Kimchi, M. Behrmann, \& C. R. Olson (Eds.), Perceptual organization in vision: Behavioral and neural perspectives (pp. 205-232). Mahwah, NJ: Erlbaum.

Palmer, S. E. (1992). Common region: A new principle of perceptual grouping. Cognitive Psychology, 24, 436-447.

Palmer, S. E. (1999). Vision science: Photons to phenomenology. Cambridge, MA: MIT Press.

Palmer, S. E., Brooks, J. L., \& Nelson, R. (2003). When does grouping happen? Acta Psychologica, 114, 311-330.

Palmer, S. E., \& Rock, I. (1994). Rethinking perceptual organization: The role of uniform connectedness. Psychonomic Bulletin \& Review, 1, 29-55.

Pani, J. R., Mervis, C. B., \& Robinson, B. F. (1999). Global spatial organization by individuals with Williams syndrome. Psychological Science, 10, 453-458.

Peterson, M. A., \& Gibson, B. S. (1994). Must shape recognition follow figure-ground organization? An assumption in peril. Psychological Science, 5, 253-259. 
Pomerantz, J. R. (1981). Perceptual organization in information processing. In M. Kubovy \& J. R. Pomerantz (Eds.), Perceptual organization (pp. 141-180). Hillsdale, NJ: Erlbaum.

Pomerantz, J. R. (1983). Global and local precedence: Selective attention in form and motion perception. Journal of Experimental Psychology: General, 112, 516-540.

Prinzmetal, W., \& Banks, W. P. (1977). Good continuation affects visual detection. Perception \& Psychophysics, 21, 389-395.

QuinN, P. C. (2002). Early categorization: A new synthesis. In U. Goswami (Ed.), Blackwell handbook of childhood cognitive development (pp. 84-101). Oxford: Blackwell.

QuinN, P. C. (2006). On the emergence of perceptual organization and categorization in young infants: Roles for perceptual process and knowledge access. In L. Balter \& C. Tamis-LeMonda (Eds.), Child psychology: A handbook of contemporary issues (2nd ed., pp. 109131). Philadelphia: Taylor \& Francis, Psychology Press

QuinN, P. C., \& BHATt, R. S. (2005). Learning perceptual organization in infancy. Psychological Science, 16, 511-515.

Quinn, P. C., Bhatt, R. S., Brush, D., Grimes, A., \& Sharpnack, H. (2002). Development of form similarity as a Gestalt grouping principle in infancy. Psychological Science, 13, 320-328.

Quinn, P. C., Brown, C. R., \& STreppa, M. L. (1997). Perceptual organization of complex visual configurations by young infants. Infant Behavior \& Development, 20, 35-46.

Quinn, P. C., Burke, S., \& Rush, A. (1993). Part-whole perception in early infancy: Evidence for perceptual grouping produced by lightness similarity. Infant Behavior \& Development, 16, 19-42.

Quinn, P. C., \& Johnson, M. H. (2000). Global-before-basic object categorization in connectionist networks and 2-month-old infants. Infancy, 1, 31-46.

QuinN, P. C., \& Schyns, P. G. (2003). What goes up may come down: Perceptual process and knowledge access in the organization of complex visual patterns by young infants. Cognitive Science, 27, 923-935.

Rogers, T. T., \& McClelland, J. L. (2004). Semantic cognition: A parallel distributed processing approach. Cambridge, MA: MIT Press.

Rovee-Collier, C. (1997). Dissociations in infant memory: Rethinking the development of implicit and explicit memory. Psychological Review, 104, 467-498.

Rush, G. P. (1937). Visual grouping in relation to age. Archives of Psychology (No. 217).
Slater, A., Morison, V., Somers, M., Mattock, A., Brown, E., \& TAYLOR, D. (1990). Newborn and older infants' perception of partly occluded objects. Infant Behavior \& Development, 13, 33-49.

Spelke, E. S. (1982). Perceptual knowledge of objects in infancy. In J. Mehler, M. Garrett, \& E. Walker (Eds.), Perspectives on mental representation (pp. 409-430). Hillsdale, NJ: Erlbaum.

SugitA, Y. (1999). Grouping of image fragments in primary visual cortex. Nature, 401, 269-272.

WERNER, H. (1957). The concept of development from a comparative and organismic point of view. In D. B. Harris (Ed.), The concept of development (pp. 125-148). Minneapolis: University of Minnesota Press.

Wertheimer, M. (1958). Principles of perceptual organization. In D. C. Beardslee \& M. Wertheimer (Eds.), Readings in perception (pp. 115 135). Princeton, NJ: Van Nostrand. (Original work published 1923)

Westheimer, G. (1999). Gestalt theory reconfigured: Max Wertheimer's anticipation of recent developments in visual neuroscience. Perception, 28, 5-15.

\section{NOTE}

1. An anonymous reviewer suggested that the distinction between EI and ES processing might apply only to 3-D object perception, as opposed to 2-D pattern perception. Our view is that the two-mechanism developmental account contrasting EI and ES processes is about perceptual unit formation, whether the units in question are derived from 2-D images or 3-D objects. As Kellman and Arterberry (1998) described the ES mechanism, "this process may be thought of as a mathematical formalization of the Gestalt principle of good continuation" (p. 143), and traditionally, Gestalt principles have been applied to 2-D images, as well as to 3-D objects. Moreover, Kellman (2003) has observed that, "straightforward extensions of the geometry of contour relatability provide a unified formal account of contour interpolation in two- and three-dimensional and spatiotemporal object perception" (p. 156). On these bases, we believe that the present results are relevant to the EI-ES model.

(Manuscript received October 20, 2004; revision accepted for publication January 24, 2005.) 